\title{
Day of the week effect on foreign exchange market volatility: Evidence from Turkey
}

\author{
Hakan Berument ${ }^{\mathrm{a}, *}$, M. Nejat Coskun ${ }^{\mathrm{b}}$, Afsin Sahin ${ }^{\mathrm{c}}$ \\ ${ }^{a}$ Department of Economics, Bilkent University, 06800 Ankara, Turkey \\ ${ }^{\mathrm{b}}$ Department of Economics, Gazi University, 06500 Ankara, Turkey \\ ${ }^{c}$ Department of Economics, Marmara University, 034180 Istanbul, Turkey
}

Received 27 April 2005; received in revised form 27 January 2006; accepted 12 March 2006

Available online 12 June 2006

\begin{abstract}
This paper assesses the day of the week effect of the daily depreciation of the Turkish lira (TL) against the US dollar (USD) and its volatility. The empirical evidence from Turkey presented here suggests that Thursdays are associated with higher and Mondays with lower depreciation rates compared to those of Wednesdays. Moreover, Mondays and Tuesdays are associated with higher volatility than Wednesdays. (C) 2006 Elsevier B.V. All rights reserved.
\end{abstract}

JEL classification: F31; C32; G14

Keywords: Exchange rate; Day of the week effect; Volatility

\section{Introduction}

The day of the week effect is often interpreted as a market anomaly (see, for example, Cornett et al., 1995). Such anomalies are often tested for developed markets and there is limited evidence from emerging markets. Moreover, most attention on the day of the week effect was focused on stock markets. However, especially in emerging markets, the foreign exchange market is the single most important financial market. The purpose of this paper is to assess this anomaly for Turkey, which is one of the few countries that has a freely floating exchange that allow us to assess (if there are any) market driven regularities (see, Reinhart and Rogoff, 2002). The Turkish

\footnotetext{
* Corresponding author. Tel.: +90 312 2902342; fax: +90 3122665140.

E-mail address: berument@bilkent.edu.tr (H. Berument).

URL: http://www.bilkent.edu.tr/ berument.
} 
lira (TL) - US dollar (USD) exchange market is sizable. For example, the Turkish lira - US dollar exchange market constitutes $0.14 \%$ of US dollar exchange in the world and Turkey is the 31st among 51 countries on US dollar trade with its own local currency, having a greater share when compared to Brazil, Thailand, Portugal, Finland, Malaysia and Argentina (see, Bank of International Settlement, 2004). The US dollar also constitutes a large share in the Turkish financial markets on trading as well. The average overnight trading in the interbank money markets between 3 January 2005 and 22 September 2005 is 2,951,878, the volume of ISE trading is 1,000,774 YTL, and the volume of the foreign exchange in interbank money markets is 6,237,631 (excluding private transactions) for this period. These clearly indicate the importance of the foreign exchange trade in Turkey and the world.

This paper assesses the day of the week effect on the foreign exchange rate and its volatility for the period between 12 March 2001 and 22 November 2005, when Turkey had a freely floating exchange rate regime. Knowledge of the properties of the daily exchange rate has important implications for economists and portfolio managers. The effects of exchange rate movements on international trade and capital flows can be vital, especially for small open economies where foreign exchange variability could affect the economic performance significantly. Moreover, understanding the day of the week effect on the exchange rate as well as on its variance could be important for portfolio managers when they construct international assets portfolios. Furthermore, knowledge of these regularities could be useful in pricing foreign currency options.

There might be various reasons for the day of the week effect. Lakonishok and Levi (1982) attribute the effect to the difference between trading time and settlement time. Domodaran (1989) argue that bad news tends to be reported on Fridays and due to delayed release of the information, Mondays are associated with lower returns. Wang et al. (1997) also report the Monday effect but only for the last 2 weeks of the month. Foster and Vishwanathan (1990) also note that Mondays have more news to evaluate; therefore trade tends to be less intensive.

There is extensive literature regarding the day of the week effect on daily depreciation (McFarland et al., 1982; Hilliard and Tucker, 1992; Cornett et al., 1995). Aydogan and Booth (2003) argued that the day of the week effect was present in the daily depreciation of the local currency in Turkey for the 1986-1994 period. Yamori and Mourdoukow (2003) investigated the day of the week effect for the Yen/US dollar exchange rate. They reported the presence of the day of the week effect for the 1973-1989 period but the effect disappeared in the 1990s. They argued that this might be due to the financial deregulation Japan made, which increased the efficiency of the financial markets. Furthermore, Yamori and Kurihara (2004) found some support for the day of the week effect for 29 foreign exchange markets in the 1980s. They also stated that the day of the week effect disappeared for almost all 29 countries in the 1990s.

A risk-averse investor is interested in not only the variation of his/her return, but also its volatility. Engle (1993) argued that investors must adjust their portfolios for the type of assets whose volatility is expected to increase. Therefore, it is important to understand any regularity that may exist in volatility. This study extends the literature by: (1) allowing the variance of the daily depreciation to be time dependent; (2) showing that this change is affected by the day of the week effect; and (3) by allowing this conditional variance to affect the exchange rate. Similar studies were performed for some foreign equity markets by Berument and Kiymaz (2001), Kiymaz and Berument (2003) and Yalcin and Yucel (2006).

Savva et al. (2005) investigated the day of the week effect by considering the 1993-2005 period for 15 European stock markets. They looked at the day of the week effect for both mean 
(return equation) and risk (variance and specification). They found that the day of the week is not significant in the mean equation but present for the variance equation in the majority of European stock markets.

The evidence presented in this paper suggests that: (1) Thursdays are associated with higher and Mondays with lower depreciation rates than Wednesdays; (2) Mondays and Tuesdays are associated with higher volatility than Wednesdays; (3) there is a positive relationship between exchange rate volatility and the daily depreciation rate; and (4) a decrease in depreciation creates more volatility compared to its increase (leverage effect). This is clearly not in line with the disappearance of the day of the week effect after 1990s as reported by Yamori and Mourdoukow (2003) and Yamori and Kurihara (2004). Our findings are similar to those of Berument and Kiymaz (2001), Kiymaz and Berument (2003), Yalcin and Yucel (2006) and Savva et al. (2005) as regards both mean and variance specifications.

This paper provides empirical evidence from Turkey on the day of the week effect. Using Turkish data has certain advantages. Firstly, Turkey is one of the few developing countries that has a freely floating exchange rate regime. This gives an idea about the regularities for the day of the week effects for other developing countries if they decide to adopt a similar regime. Secondly, Turkey has well developed financial markets. Therefore, the empirical evidence is more likely due to the workings of financial markets rather than policy induced shocks. Thirdly, Turkish financial markets are highly volatile. This helps us to avoid the type 2 error-not rejecting the null hypothesis when it is false.

In the following section, we briefly review foreign exchange rate changes in Turkey by observing the political and economic developments. Section 3 introduces the data and methodology. Section 4 discusses the empirical evidence and the last section provides the conclusions.

\section{Developments in the Turkish foreign exchange rate market}

Following the financial crisis that was triggered by a speculative attack on 19 February 2001, the Central Bank of the Republic of Turkey (henceforth, CBRT) let the exchange rate float. During the exchange rate based disinflation program that was implemented between 1 January 2000 and 23 February 2001, Turkey adopted a crawling peg exchange rate regime. During this period, there was a significant increase in the foreign exchange open positions of commercial banks and companies. Expectations concerning the possibility of an imminent collapse of the IMF supported stability program based on a crawling peg started rising in November 2000, when there was a speculative attack on foreign currency. This was successfully contained by late December 2000. However, a second and an even more powerful attack on foreign currency, triggered by a domestic political crisis, started on the 19th of February: Foreign exchange demand skyrocketed and the Central Bank reserves took a sharp dive. This time the attack on the local currency could not be contained. The government felt it had to abandon the peg, make a "surgical" overnight devaluation of about $35 \%$ on the 22 February and then switch to a floating rate regime on the 23 February 2001. Capital outflows, however, continued for another few weeks, during which foreign exchange demand remained high and markets further devalued the local currency.

The CBRT started conducting regular auctions for the sale of foreign exchange in late March 2001 in order to smooth the effects of temporary exchange rate fluctuations without (they claim) affecting the long run equilibrium level of the exchange rate. There were two other factors contributing to the fluctuations in the exchange rate in the second half of 2001: (i) the so called 
"TELEKOM crisis"1 in July due to the dispute concerning the privatization of the Turkish telecommunication monopoly; and (ii) the repercussions of the terrorist attacks on the US on 11 September 2001. USD/TL parity reached its 2001 peak level of $1 \$=1,627,457$ in early October.

After September, foreign exchange auctions were conducted daily for US\$ 20 million. This strategy was pursued in order to prevent liquidity from increasing in excessive amounts on certain days and to smooth excess fluctuations in the exchange rate. Partially as a result of these policies (but more so because economic agents realized that the worst of the financial crisis was over and that the TL was, if anything, undervalued), exchange rate volatility declined considerably in the last quarter of 2001. Moreover, the Turkish lira started once again to gain real value, though not before sliding rather steeply for about a month and a half following the 11 September attacks in the US.

Throughout the first quarter of 2002, the resolute implementation of fiscal and monetary policies in line with the predetermined targets of the new stability program, increasing foreign financing opportunities, the actualization of some structural reforms and positive developments in the current account balance (which had yielded a positive balance in 2001) brought about the desired stability in the exchange rate. In the few months following April 2002, however, risk perception in the markets started to increase again and the Turkish lira began to depreciate once more in spite of the fact that it was in no way overvalued. The main reasons behind this new short-term reversal of the trend in the late spring and early summer of 2002 were disputes between the governing coalition partners about the draft laws for harmonization with EU legislation and other adverse domestic political developments.

The announcement of the early election date and the adoption of laws to achieve EU membership helped to stop the real depreciation of the TL. It started to appreciate in mid September, when public opinion polls indicated that there was a very good chance that the elections scheduled for the 3 November were likely to yield a clear parliamentary majority for one of the contending parties, namely the AKP (Justice and Development Party), bringing longed-for stability to the political scene. The real appreciation of the TL gained momentum immediately after the 3 November elections (which indeed resulted in a clear parliamentary majority for the AKP), a trend that lasted until late December 2002. During the next 3 months, however, concerns about an impending US military operation in Iraq, the confusion and uncertainties regarding possible Turkish military involvement in Iraq and the resulting fluctuations in Turkish-US relations created an increased volatility in the market and the TL experienced real depreciation during the first 3 months of 2003. Meanwhile, the nominal exchange rate increased to its historical peak level on 25 March: $1 \$=1,746,390 \mathrm{TL}$-although this nominal peak did not, of course, represent a peak in real terms compared to the crises period.

The end of the war in Iraq as declared by President Bush on 1 May 2003 eased these uncertainties. As a result, the Turkish lira started to experience a rather rapid appreciation as of the last week of May and this trend persisted throughout 2003, during which year the economy seemed to have overcome the adverse effects of the financial crisis of February 2001 and achieved a robust rate of growth $(5.8 \%)$ coupled with a surge in exports and a sustainable-looking current account

\footnotetext{
${ }^{1}$ Arguing that telecommunications had strategic importance since the armed forces also used the services provided by this public monopoly, the nationalist-rightist partner of the tripartite coalition, the Nationalist Action Party, opposed the plan drawn-up for the prospective privatization of the Turkish TELEKOM. This plan had been included in the letter of intent the government presented to the IMF. This implied a substantial rift between the coalition partners and added to the expectations that the coalition was likely to collapse in the near future.
} 
deficit of about $2.4 \%$ of the GNP. The downward trend in the nominal exchange rate (which meant that the Turkish lira was gaining real value at an even faster pace) continued in the first quarter of 2004. This occurred in spite of regular weekly purchasing auctions of foreign exchange that were held by the Central Bank of the Republic of Turkey, which aimed at damping excessive volatility. The slide of the nominal exchange rate from its 25 March peak lasted for about a year, albeit with some fluctuations. It seems to have bottomed out at about 1 US $\$=1,310,000$ TL in March 2004.

The USD selling rate started to fluctuate around 1,350,000 TL between the period of 1 January and 22 November 2005. The instantaneous rises and falls in the exchange rate have tailed off compared with the previous terms. Exchange rate stability was reflected positively to the banking and finance sector. Asset quality of the banking sector was increased after the previous economic and social crises of 2001. In exchange rate risk, the banking sector has become much more stabilized. The banking sector had experienced a loss in the 1999-2001 period, but in the balance sheets, the conversion of this loss into profit continued increasingly. Financial deepening and strength structure had increased to the highest level of the previous 5 years as of December 2004. As of 22 November 2005, the strength of the banking sector's financial structure continues. The CBRT aims to prevent fluctuations by the highly qualified management of foreign currency reserves for dependable investment and macroeconomic stability in the price system. The CBRT controls liquidity, operational and foreign currency risks minutely by using the latest financial risk management techniques. With regards to unanticipated and undetermined risks, CBRT tries to take preventive measures as much as possible (see, CBRT, 2005).

\section{Data and methodology}

We used daily data starting on 12 March $2001^{2}$ and ending on 22 November 2005 . The depreciation of local currency against the USD is calculated as the growth of the TL value of the USD.

$$
R_{t}=\left(\frac{P_{t}}{P_{t-1}}-1\right) \times 100
$$

where $P_{t}$ is the Turkish lira value of the US dollar and $R_{t}$ the daily depreciation rate of the Turkish lira. In order to model the exchange rate, we regressed the depreciation rate on the constant term with four daily dummies to account for the day of the week effect. Most of the studies searching for the day of the week effect in the depreciation rate (e.g. Aydogan and Booth, 2003, for Turkey) use the standard ordinary least square method, which has two drawbacks. Firstly, errors in the model may be auto-correlated, resulting in misleading inferences. Secondly, error variances may not be constant over time, which means heteroscedasticity. In order to account for the auto-correlation problem, we can include lagged values of the depreciation rates in the equation:

$$
R_{t}=\alpha_{0}+\alpha_{M} M_{t}+\alpha_{t} T_{t}+\alpha_{H} H_{t}+\alpha_{F} F_{t}+\sum_{i=1}^{n} \alpha_{i} R_{t-i}+\varepsilon_{t}
$$

\footnotetext{
2 After the financial crisis in 2001, Turkey had a 9-day religious holiday. Twelve March 2001 was the very first business day after that holiday. That date is often taken as the beginning of the freely floating exchange rate.
} 
where $M_{t}, T_{t}, H_{t}$ and $F_{t}$ are the dummy variables for Monday, Tuesday, Thursday and Friday at time $t$, and $n$ is the lag order. ${ }^{3}$ Here, we exclude the dummy variable for Wednesday in order to avoid the dummy variable trap.

In order to consider the second problem, we allow variances of errors to be time dependent where $e_{t}\left(0, h_{t}^{2}\right)$. In order to model the conditional variance, we adopt Nelson (1991)'s exponential generalized autoregressive conditional heteroscedastic (EGARCH) models. To be more specific, we have modeled the conditional variance $h_{t}^{2}$ as

$$
\log h_{t}^{2}=\kappa+\delta_{1} \log h_{t-1}^{2}+\gamma_{1}\left(\left|\frac{\varepsilon_{t-1}}{h_{t-1}}\right|-E\left|\frac{\varepsilon_{t-1}}{h_{t-1}}\right|+\chi \frac{\varepsilon_{t-1}}{h_{t-1}}\right)
$$

In order to account for the excess kurtosis, errors are assumed to have a general error distribution. Therefore, $E\left|\varepsilon_{t} / h_{t}\right|=\Lambda 2^{1 / D}(\Gamma(2 / D)) /(\Gamma(1 / D))$, where $\Gamma(\cdot)$ is the gamma function, $\Lambda=\sqrt{2^{-2 / D}}(\Gamma(1 / D)) /(\Gamma(3 / D))$ and $D$ the parameter for the general error distribution. $D$ is a positive parameter to account for the thickness of the tails. If $D=2$, then the distribution is normal; if $D<2$, then the density has thicker tails than the normal distribution; and if $D>2$, then the density has thinner tails. If high variability follows high variability, and low variability follows low variability - indicating the presence of the ARCH effect - then this requires thick tails and it can be expected that the estimated coefficient for $D$ will be less than 2 .

The EGARCH specification has certain advantages. The conditional variance is in logarithmic form, which allows that $h_{t}^{2}$ can never be negative. It also allows the leverage effect: if $\chi=0$, then a positive $\left(\varepsilon_{t-1} / h_{t-1}>0\right)$ has the same magnitude effect as a negative surprise; if $-1<\chi<0$, a positive surprise increases volatility less than a negative surprise does; if $\chi<-1$, then a positive surprise decreases volatility while a negative surprise increases volatility.

It is possible that the conditional variance as proxy for risk can affect the foreign exchange rate. We consider various models to be investigated for the day of the week effect in both depreciation and volatility equations. Our first model consists of the following two equations:

$$
\begin{aligned}
& R_{t}=\alpha_{0}+\alpha_{M} M_{t}+\alpha_{t} T_{t}+\alpha_{H} H_{t}+\alpha_{F} F_{t}+\sum_{i=1}^{n} \alpha_{i} R_{t-i}+\lambda h_{t}^{2}+\varepsilon_{t} \\
& \log h_{t}^{2}=\kappa+\delta_{1} \log h_{t-1}^{2}+\gamma_{1}\left(\left|\frac{\varepsilon_{t-1}}{h_{t-1}}\right|-E\left|\frac{\varepsilon_{t-1}}{h_{t-1}}\right|+\chi \frac{\varepsilon_{t-1}}{h_{t-1}}\right)
\end{aligned}
$$

The estimated positive $\lambda$ suggests that risk-averse agents must be compensated to accept higher risk. Here, we take into account the possibility that the lagged values of the squared residuals and the conditional variances might be too restrictive.

Some studies in the literature suggest the inclusion of exogenous variables in the ARCH specifications. For example, Karolyi (1995) includes the volatility of foreign stock returns to explain the conditional variance of home country stock returns. Hsieh (1988) includes the day of the week effect in volatility for various exchange rates. Following Hsieh (1988) and Karolyi (1995), we model the conditional variability of depreciation by incorporating the day of the week

\footnotetext{
${ }^{3}$ One way to determine the optimum lag order $n$ is to use the final prediction error criteria (FPEC), which determine $n$ such that it eliminates autocorrelation in the residual term. If the residuals were auto-correlated, ARCH-LM tests would suggest the presence of heteroscedasticity in the residual term even if the residuals were homoskedastic (see Cosimano and Jansen, 1988).
} 
effect into our volatility equation. In this way, we allow the constant term of the conditional variance equation to vary for each day. Therefore, our second model is specified as follows:

$$
\begin{aligned}
R_{t}=\alpha_{0} & +\alpha_{M} M_{t}+\alpha_{t} T_{t}+\alpha_{H} H_{t}+\alpha_{F} F_{t}+\sum_{i=1}^{n} \alpha_{i} R_{t-i}+\lambda h_{t}^{2} \\
\log h_{t}^{2}= & \kappa+\beta_{M} M_{t}+\beta_{T} T_{t}+\beta_{H} H_{t}+\beta_{F} F_{t}+\delta_{1} \log h_{t-1}^{2} \\
& +\gamma_{1}\left(\left|\frac{\varepsilon_{t-1}}{h_{t-1}}\right|-E\left|\frac{\varepsilon_{t-1}}{h_{t-1}}\right|+\chi \frac{\varepsilon_{t-1}}{h_{t-1}}\right)
\end{aligned}
$$

Here we use the Quasi-maximum likelihood estimation (QMLE) method introduced by Bollerslev and Wooldridge (1992) to estimate parameters. ${ }^{4}$

\section{Empirical evidence}

The Table 1 reports the estimates of the specifications in (5a) and (5b). Column A reports the estimates for the full sample. First, we will discuss the estimates of the mean equation (Eq. (5a)): the estimated coefficient for $H_{t}$ is the highest and the lowest is for $M_{t}$. (Note that we exclude a dummy variable for Wednesday to avoid the dummy variable trap; therefore, the coefficient should be comparable to the daily depreciation rates of Wednesdays.) This suggests that the highest returns are observed for Thursdays and the lowest returns for Mondays. However, none of these coefficients are statistically significant. ${ }^{5}$ This suggests that none of these days offer statistically significant higher returns when compared to Wednesdays. On the other hand, the estimated coefficients for $M_{t}, T_{t}, H_{t}$, and $F_{t}$ are jointly statistically significant. This suggests that the day of the week effect is present. Moreover, the estimated coefficient for the mean ( $\lambda$ in Eq. (5a)) is positive and statistically significant. This suggests that agents want to be compensated for holding riskier assets with higher returns.

Next, we elaborate on the estimates of the conditional variance specification. The estimated coefficient for the leverage effect, $\chi$, is negative, between -1 and 0 , and statistically significant. This suggests that negative unanticipated change in the depreciation equation introduces more of a change in conditional variance than positive unanticipated change does. The coefficient for $\delta_{1}$ is less than 1 , and this satisfies the non-explosiveness of conditional variance. The highest variances are observed on Thursdays and the lowest variances on Wednesdays. $D$ is the parameter for the general error distribution. Note that the estimated coefficient for $D$ is always positive and less than two. This suggests the presence of thick tails - leading to the presence of the ARCH effect - compared with normal distribution.

In order to assess the robustness of our specification, we provided a set of robustness statistics. The first types of test statistics are nonparametric sign and size bias tests. In particular, we

\footnotetext{
${ }^{4}$ Pagan (1984) argues that the use of a stochastic regressor gives biased estimates. Pagan and Ullah (1988) suggest the use of the full information maximum likelihood estimation (MLE) technique to estimate the system of equation to avoid bias. Bollerslev and Wooldridge (1992), on the other hand, question the assumption concerning the normality of the standardized conditional errors $\varepsilon_{t} / h_{t}$ and argue that this assumption may cause misspecification of the likelihood function. Bollerslev and Wooldrige suggest the use of the QMLE method to avoid the misspecification problem. They formally show that the QMLE is generally consistent and has a limited distribution. Following their discussion, we use the QMLE method in our estimation.

5 Significance is at the $5 \%$ level unless otherwise noted.
} 
Table 1

The day of the week effect on the Turkish foreign exchange market

\begin{tabular}{|c|c|c|c|}
\hline & Full sample & Pre-April & Post-April \\
\hline \multicolumn{4}{|l|}{ Mean specification } \\
\hline Constant & $\begin{array}{l}-20.6073 \\
{[0.0053]}\end{array}$ & $\begin{array}{l}-0.0019 \\
{[0.1100]}\end{array}$ & $\begin{array}{l}-15.6815 \\
{[0.1030]}\end{array}$ \\
\hline$R_{t-1}$ & $\begin{array}{l}0.0536 \\
{[0.0866]}\end{array}$ & $\begin{array}{l}0.1260 \\
{[0.0027]}\end{array}$ & $\begin{array}{c}-0.0002 \\
{[0.9968]}\end{array}$ \\
\hline$R_{t-2}$ & $\begin{array}{l}-0.0929 \\
{[0.0021]}\end{array}$ & $\begin{array}{l}-0.1165 \\
{[0.0038]}\end{array}$ & $\begin{array}{l}-0.0615 \\
{[0.1459]}\end{array}$ \\
\hline$M_{t}$ & $\begin{array}{c}-8.8853 \\
{[0.1360]}\end{array}$ & $\begin{array}{l}-0.0012 \\
{[0.2579]}\end{array}$ & $\begin{array}{c}-8.9304 \\
{[0.1921]}\end{array}$ \\
\hline$T_{t}$ & $\begin{array}{l}4.8842 \\
{[0.4456]}\end{array}$ & $\begin{array}{l}0.0012 \\
{[0.2795]}\end{array}$ & $\begin{array}{l}-2.1251 \\
{[0.7959]}\end{array}$ \\
\hline$H_{t}$ & $\begin{array}{l}9.8069 \\
{[0.1055]}\end{array}$ & $\begin{array}{l}0.0009 \\
{[0.4201]}\end{array}$ & $\begin{array}{l}9.4481 \\
{[0.1781]}\end{array}$ \\
\hline$F_{t}$ & $\begin{array}{l}2.4702 \\
{[0.6768]}\end{array}$ & $\begin{array}{l}-0.0016 \\
{[0.0960]}\end{array}$ & $\begin{array}{l}7.4557 \\
{[0.3102]}\end{array}$ \\
\hline$\lambda$ & $\begin{array}{l}0.1805 \\
{[0.0376]}\end{array}$ & $\begin{array}{l}0.1936 \\
{[0.0604]}\end{array}$ & $\begin{array}{l}0.1302 \\
{[0.4095]}\end{array}$ \\
\hline \multicolumn{4}{|l|}{ Variance specification } \\
\hline Constant & $\begin{array}{l}0.5474 \\
{[0.0137]}\end{array}$ & $\begin{array}{c}-0.8453 \\
{[0.0063]}\end{array}$ & $\begin{array}{l}0.3332 \\
{[0.3617]}\end{array}$ \\
\hline$\chi$ & $\begin{array}{l}-0.2875 \\
{[0.0039]}\end{array}$ & $\begin{array}{c}-0.3693 \\
{[0.0000]}\end{array}$ & $\begin{array}{c}-0.4004 \\
{[0.0515]}\end{array}$ \\
\hline$\delta_{1}$ & $\begin{array}{l}0.9077 \\
{[0.0000]}\end{array}$ & $\begin{array}{l}0.9171 \\
{[0.0000]}\end{array}$ & $\begin{array}{l}0.8909 \\
{[0.0000]}\end{array}$ \\
\hline$\gamma_{1}$ & $\begin{array}{l}0.3930 \\
{[0.0000]}\end{array}$ & $\begin{array}{l}-0.4307 \\
{[0.0264]}\end{array}$ & $\begin{array}{l}0.2990 \\
{[0.0004]}\end{array}$ \\
\hline$M_{t}$ & $\begin{array}{l}0.0220 \\
{[0.9047]}\end{array}$ & $\begin{array}{l}0.2167 \\
{[0.4830]}\end{array}$ & $\begin{array}{l}0.1593 \\
{[0.5367]}\end{array}$ \\
\hline$T_{t}$ & $\begin{array}{l}0.7416 \\
{[0.0015]}\end{array}$ & $\begin{array}{l}0.3491 \\
{[0.3897]}\end{array}$ & $\begin{array}{l}1.2414 \\
{[0.0003]}\end{array}$ \\
\hline$H_{t}$ & $\begin{array}{l}0.2074 \\
{[0.3565]}\end{array}$ & $\begin{array}{l}-0.0013 \\
{[0.9974]}\end{array}$ & $\begin{array}{l}0.6855 \\
{[0.0355]}\end{array}$ \\
\hline$F_{t}$ & $\begin{array}{l}0.2947 \\
{[0.1615]}\end{array}$ & $\begin{array}{l}-0.1877 \\
{[0.5677]}\end{array}$ & $\begin{array}{l}0.7574 \\
{[0.0052]}\end{array}$ \\
\hline$D$ & $\begin{array}{l}1.3176 \\
{[0.0000]}\end{array}$ & $\begin{array}{l}1.1302 \\
{[0.0000]}\end{array}$ & $\begin{array}{l}1.5451 \\
{[0.0000]}\end{array}$ \\
\hline \multicolumn{4}{|l|}{ Robustness test } \\
\hline Sign bias test & {$[0.8433]$} & {$[0.6443]$} & {$[0.4822]$} \\
\hline Negative size bias test & [0.6343] & {$[0.9820]$} & {$[0.3690]$} \\
\hline Positive size bias test & {$[0.2775]$} & {$[0.3551]$} & {$[0.3696]$} \\
\hline Joint test for the three effects & {$[0.3812]$} & {$[0.5567]$} & {$[0.4433]$} \\
\hline $\begin{array}{l}\operatorname{AR}(5) \\
\operatorname{AR}(10) \\
\operatorname{AR}(20) \\
\operatorname{AR}(60)\end{array}$ & $\begin{array}{l}{[0.9661]} \\
{[0.4081]} \\
{[0.1670]} \\
{[0.2399]}\end{array}$ & $\begin{array}{l}{[0.9437]} \\
{[0.6707]} \\
{[0.8641]} \\
{[0.2154]}\end{array}$ & $\begin{array}{l}{[0.9601]} \\
{[0.7165]} \\
{[0.8714]} \\
{[0.1307]}\end{array}$ \\
\hline ARCH-LM(5) & {$[0.4820]$} & {$[0.6744]$} & {$[0.5474]$} \\
\hline ARCH-LM(10) & [0.1998] & {$[0.9120]$} & {$[0.8743]$} \\
\hline ARCH-LM(20) & {$[0.5081]$} & {$[0.9930]$} & {$[0.6972]$} \\
\hline ARCH-LM(60) & {$[0.2365]$} & {$[0.8861]$} & {$[0.1839]$} \\
\hline
\end{tabular}

Note: $p$-values are reported in branches. 
conducted: (1) sign bias test; (2) negative size bias test; (3) positive size bias test; and (4) joint tests. In order to calculate these test statistics, we define the standardized residual by dividing the estimated residual by the conditional standard errors $\left(\varepsilon_{t}=\varepsilon_{t} / h_{t}\right){ }^{6}$ As a result of these tests (see Table 1 for the $p$-values), it is observed that all the bias tests fail to reject the null hypothesis and the sign and the size effects are not present.

Next, we conduct the Ljung-Box auto-correlation test for 5, 10, 20 and 60 lags by using the standardized residuals. None of the $p$-values that are reported in the table suggest the presence of autocorrelations, which supports the validity of our specification. Finally, we performed the ARCH-LM test for 5, 10, 20 and 60 lags. To be specific, we regressed squared standardized residuals to a constant term for 5, 10, 20 and 60 lags. Then, we tested whether these lag terms jointly were statistically significant. The $p$-values are reported in the last four rows of the table. We cannot reject the null hypothesis that all these added lag terms are statistically significant at the conventional 5\% level. In summary, all these robustness tests support the validity of our specification.

March 2003 was the month when, nominally, the exchange rate reached its historical peak. Thus, we split the sample in two, as pre- and post-April 2003. Panel B reports the estimates for the preApril 2003 period and panel C reports the estimates for the post-April 2003 period. The estimates quoted in these panels suggest that Mondays have lower returns than Wednesdays, and Thursdays have higher returns than Wednesdays. Moreover, the positive relationship between exchange rate volatility and exchange rate changes is positive, even if the coefficient is not statistically significant for the post-April period and statistically significant for the pre-April 2003 period at the $6 \%$ level. As for the conditional variance specification, the results indicate that Mondays and Tuesdays have higher volatility than Wednesdays. Even if the pattern of the day of the week effects does change across sub-periods, these effects show some regularities; Mondays are always associated with lower returns and Thursdays with higher returns than Wednesdays in the mean specification. Lastly, the day of the week dummies are jointly statistically significant for both the return (mean) and the volatility (variance) equations. Thus, we may conclude that the day of the week effect on both conditional mean and variance is present in the Turkish foreign exchange market.

\section{Conclusion}

This paper assesses the day of the week effect on foreign exchange rate changes and their volatility with an EGARCH specification. The day of the week effects are presented in mean and volatility specifications. The evidence presented in this paper suggests that: (1) Thursdays are associated with higher and Mondays with lower returns when compared to Wednesdays; (2) Mondays and Tuesdays are associated with higher volatility than Wednesdays; (3) there is a positive relationship between exchange rate volatility and the daily depreciation rate; and (4) a decrease in depreciation creates more volatility than an increase (the leverage effect).

The efficient market hypothesis implies that investors will develop strategies to explore any regulatory pattern that may exist in financial markets. Therefore, the presence of the day of the week effect as one of the most important financial market anomalies is often promoted as a conflict

\footnotetext{
${ }^{6}$ In order to perform these tests, two dummy variables $-m(t)$ and $p(t)-$ are defined such that $m(t)=1$ if the normalized residual is negative, 0 otherwise; and $p(t)=1$ if it is positive and 0 otherwise. Then two interactive dummy variables are defined as $\operatorname{sm}(t)=p(t) \cdot e(t)$ and $\operatorname{sp}(t)=p(t) \cdot e(t)$. Then $e(t)$ is regressed on the constant terms $m$, sm, sp and the equation is estimated. In the sign test, $H_{\mathrm{o}}: m(t)=0$ is tested; and for the negative sign test $H_{\mathrm{o}}: \operatorname{sm}(t)=0$ is tested. For the positive size test, $H_{\mathrm{O}}: \mathrm{sp}(t)=0$ is tested; and for the joint test the null hypothesis are jointly tested.
} 
with the efficient market hypothesis. Similarly, the disappearance of the day of the week effect is interpreted as higher efficiency in the markets (see, for example, Yamori and Mourdoukow, 2003). Kohers et al. (2004) note transaction cost and time varying risk premium as sources of the regularity, which may not be tied to market (in) efficiency directly. However, Yamori and Kurihara (2004) tie this disappearance in financial markets to deregulation and globalization. This study is an attempt to account for the time varying risk premium and show that the day of the week effect is present in the Turkish foreign exchange market. Thus, one may concentrate on transaction cost or other determinants of inefficiency by deregulating the financial markets and helping the acceleration of globalization to boost the efficiency in the Turkish foreign exchange market.

\section{Acknowledgements}

We would like to thank Anita Akkas and Kemal Cakman for their invaluable suggestions.

\section{References}

Aydogan, K., Booth, G., 2003. Calendar anomalies in the Turkish foreign exchange markets. Appl. Finan. Econ. 13, $353-360$.

Berument, H., Kiymaz, H., 2001. The day of the week effect on stock market volatility. J. Econ. Finan. 25, $181-193$.

Bollerslev, T., Wooldridge, L.M., 1992. Quasi-maximum likelihood estimation and inference in dynamic models with time-varying covariances. Econ. Rev. 11, 43-72.

CBRT, 2005. Financial stabilization report 1 August, pp. 47-135, available at: http://www.tcmb.gov.tr/yeni/evds/ yayin/finist/finist.php (in Turkish).

Cornett, M.M., Schwarz, V., Szakmary, A.C., 1995. Seasonalities and intraday return patterns in the foreign currency futures market. J. Banking Finan. 19, 843-869.

Cosimano, T.F., Jansen, D.W., 1988. Estimates of the variance of US inflation based upon ARCH model. J. Bus. Finan. Accounting 21, 271-282.

Domodaran, A., 1989. The weekend effect in information releases: a study of earnings and dividend announcement. Rev. Finan. Stud. 2, 607-623.

Engle, R., 1993. Statistical models for financial volatility. Finan. Anal. J. (January-February), 72-78.

Foster, D., Vishwanathan, S., 1990. A theory of intraday variations in volume, variance and trading costs in security markets. Rev. Finan. Stud. 3, 593-624.

Hilliard, J.E., Tucker, A.L., 1992. A note on weekday, intraday, and overnight patterns in the interbank foreign exchange and listed currency options markets. J. Banking Finan. 16, 1159-1171.

Hsieh, D.A., 1988. The statistical properties of daily foreign exchange rates: 1974-1983. J. Int. Econ. 24, 129-145.

Karolyi, A.G., 1995. A multivariate GARCH model of international stock returns and volatility: the case of the United States and Canada. J. Bus. Econ. Stat. 13, 11-25.

Kiymaz, H., Berument, H., 2003. The day of the week effect on stock market volatility and volume: international evidence. Rev. Finan. Econ. 12, 363-380.

Kohers, G., Kohers, N., Pandey, V., Kohers, T., 2004. The disappearing day-of-the-week effect in the world's largest equity markets. Appl. Econ. Lett. 11, 167-171.

Lakonishok, J., Levi, M., 1982. Weekend effects on stock returns: a note. J. Finan. 37, 883-889.

McFarland, J.W., Richardson, P., Pettit, R., Sung, S.K., 1982. The distribution of foreign exchange price changes: trading day effects and risk measurement. J. Finan. 37, 693-715.

Nelson, D.B., 1990. Conditional heteroskedasticity in asset returns: a new approach. Econometrica 59, 347-370.

Pagan, A., 1984. Econometric analysis of models with risk term. J. Appl. Econ. 3, 87-105.

Pagan, A., Ullah, A., 1988. New findings regarding day-of-the week returns over trading and nontrading periods: a note. J. Finan. 35, 1603-1614.

Reinhart, C.M., Rogoff, K.S., 2002. The modern history of exchange rate arrangements: a reinterpretation. NBER Working Paper 8963, pp. 1-106, available at: http://www.nber.org/papers/8963.

Savva, C., Osborn, D., Gill, L., 2005. The day of the week effect on stock market volatility using EGARCH framework. University of Manchester, mimeo, available at: http://www.socialsciences.manchester.ac.uk/economics/ research/phd/csavva/paper_1b.pdf. 
Wang, K., Li, Y., Erickson, J., 1997. A new look at the Monday effect. J. Finan. LII, 2171-2186.

Yalcin, Y., Yucel, E., 2006. The day of the week effect on stock market volatility: evidence from emerging markets. Czech. J. Econ. Finan. (forthcoming).

Yamori, N., Mourdoukow, P., 2003. Does the day-of the week effect in foreign currency markets disappear? Evidence from the Yen/Dollar market. Int. Finan. Rev. 4, 447-463.

Yamori, N., Kurihara, Y., 2004. The day-of-the-week effect in foreign exchange markets: multi-currency evidence. Res. Int. Bus. Finan. 18, 51-57. 